\title{
Depression in adolescence: a review
}

\author{
Diogo Beirão $^{1 *}$ D, Helena Monte ${ }^{1}$, Marta Amaral ${ }^{1}$, Alice Longras ${ }^{1}$, Carla Matos ${ }^{1,2}$ and Francisca Villas-Boas ${ }^{1}$
}

\begin{abstract}
Background: Depression is a common mental health disease, especially in mid to late adolescence that, due to its particularities, is a challenge and requires an effective diagnosis. Primary care providers are often the first line of contact for adolescents, being crucial in identifying and managing this pathology. Besides, several entities also recommend screening for depression on this period. Thus, the main purpose of this article is to review the scientific data regarding screening, diagnosis and management of depression in adolescence, mainly on primary care settings.

Main body: Comprehension of the pathogenesis of depression in adolescents is a challenging task, with both environmental and genetic factors being associated to its development. Although there are some screening tests and diagnostic criteria, its clinical manifestations are wide, making its diagnosis a huge challenge. Besides, it can be mistakenly diagnosed with other psychiatric disorders, making necessary to roll-out several differential diagnoses. Treatment options can include psychotherapy (cognitive behavioural therapy and interpersonal therapy) and/or pharmacotherapy (mainly fluoxetine), depending on severity, associated risk factors and available resources. In any case, treatment must include psychoeducation, supportive approach and family involvement. Preventive programs play an important role not only in reducing the prevalence of this condition but also in improving the health of populations.

Conclusion: Depression in adolescence is a relevant condition to the medical community, due to its uncertain clinical course and underdiagnosis worldwide. General practitioners can provide early identification, treatment initiation and referral to mental health specialists when necessary.
\end{abstract}

Keywords: Depression, Adolescence, Diagnosis, Treatment

\section{Background}

Adolescence is an important period in developing knowledge and skills, learning how to manage emotions and relationships and acquiring attributes and abilities for adulthood. Depression in adolescence is a common mental health disease with a prevalence of $4-5 \%$ in $\mathrm{mid}$ to late adolescence [1]. It is a major risk factor for suicide and can also lead to social and educational impairments. Consequently, identifying and treating this disorder is crucial.

General practitioners and primary care providers are frequently the first line of contact for adolescents in

\footnotetext{
*Correspondence: diogobeirao10@gmail.com

'Family Health Unit of Ramalde, Health Centres Grouping of Porto Ocidental, Porto, Portugal

Full list of author information is available at the end of the article
}

times of distress and can be crucial to identify mental health issues amongst these patients. They can facilitate early identification of depression, initiate treatment and refer the adolescents for mental health specialists [2]. It is vital to make a timely and accurate diagnosis of depression in adolescence and a correct differential diagnosis from other psychiatric disorders, due to the recurrent nature of this condition and its association with poor academic performance, functional impairment and problematic relationships with parents, siblings and peers. Furthermore, depression at this age is strongly related to suicidal ideation and attempts [2].

The US Preventive Services Task Force (USPSTF) recommends screening adolescents for depressive disorder by the General Practitioners [2, 3]. Guidelines from the American Academy of Pediatrics (AAP) state that

\section{Springer Open}

(c) The Author(s). 2020 Open Access This article is licensed under a Creative Commons Attribution 4.0 International License, which permits use, sharing, adaptation, distribution and reproduction in any medium or format, as long as you give appropriate credit to the original author(s) and the source, provide a link to the Creative Commons licence, and indicate if changes were made. The images or other third party material in this article are included in the article's Creative Commons licence, unless indicated otherwise in a credit line to the material. If material is not included in the article's Creative Commons licence and your intended use is not permitted by statutory regulation or exceeds the permitted use, you will need to obtain permission directly from the copyright holder. To view a copy of this licence, visit http://creativecommons.org/licenses/by/4.0/. 
adolescent patients should be screened annually for depression in Primary Care with a formal self-report screening tool [4]. AAP recommends that Primary Care clinicians should evaluate for depression in those who screen positive on the screening tool, in those who present with any emotional problem as the chief complaint and in those in whom depression is highly suspected despite a negative screen result [4].

The present work consists of a review on the depression in the adolescent, summarizing data published in scientific papers in the last years, regarding the epidemiology of the disease, its pathogenesis and risk factors, screening and diagnosis tools and its management and treatment. Our research focused on research papers published between January 2010 and March 2020 in the area. Other research papers not included in this first search were included due to their interest and value to the subject. The keywords, used in different permutations and combinations, included the following: depression, adolescence, overview, pathophysiology, diagnosis and treatment.

\section{Epidemiology}

The prevalence of depression is significantly linked to age, being low in children $(<1 \%)$ and increasing throughout childhood and adolescence. Nevertheless, the prevalence of depression in adolescence varies significantly between studies and reports. A reported prevalence in Great Britain was $4 \%$, whereas in the USA was $2.1 \%$ and in France was $11.0 \%$ [5-7]. Nevertheless, a systematic review from 2013 stated the life prevalence of depression varies from 1.1 to $14.6 \%$ [8].

A possible factor for the reported increase during adolescence is the set of social and biological changes characteristic of post-pubertal phase, such as enhanced social understanding and self-awareness, brain circuits changes involved in responses to reward and danger and increased reported stress levels [9-11].

Regarding differences between genders, while no significant differences are found in depression during childhood, depression during adolescence has a strong female preponderance, similar to adulthood [12-14]. This difference is still observed between distinct epidemiological and clinical samples and across various methods of assessment. As such, it is unlikely due to differences in help-seeking or reporting of symptoms and more closely tied to female hormonal changes, which suggests a direct link to hormone-brain relations [15].

\section{Pathogenesis}

Comprehension of the pathogenesis of depression in adolescents is a challenging task, due to its heterogeneous clinical presentation and diverse causes.
Putative risk factors, potentially modifiable during adolescence without professional intervention, are substance use (alcohol, cannabis and other illicit drugs, tobacco), diet and weight [16].

Alcohol use is known to have neurotoxic effects during this developmentally sensitive period. Cannabis and other illicit drugs can have an impact on serotonin and other neurotransmitters causing an increase in depressive symptoms. Furthermore, alcohol, cannabis and other illicit drug use have various deleterious social and academic consequences for the adolescent which could increase their risk for depression [16].

The relationship between tobacco use and depression is unclear. However, it has been proposed that this linkage may arise from the effects of nicotine on neurotransmitter activity in the brain, causing changes to neurotransmitter activity [17]. Overweight can have a negative impact on self-image which elevates the risk for depression. Moreover, depressed people may lead a less healthy lifestyle and suffer from deregulation in the stress response system, which may contribute to weight gain [16].

Association between depression and environmental factors, such as exposures to acute stressful events (personal injury, bereavement) and chronic adversity (maltreatment, family discord, bullying by peers, poverty, physical illness), has been subject of papers. Stressful life events seem more strongly associated with first onset rather than recurrence, and risk is considerably greater in girls and in adolescents who have multiple negative life events. The most important factors are chronic and severe relationship stressors [18]. A significant interaction was found between exposure to maternal threatening behaviours and deficits in emotional clarity in relation to depressive symptom severity [19].

Genetic factors can also play a very important role in the pathogenesis. Many reports suggest that a variant (5HTTLPR) in the serotonin transporter gene might increase the risk of depression, but only in the presence of adverse life stressors or early maltreatment. The findings are less robust in adolescent boys than girls. This gene variant has also been reported to affect fear-related and danger-related brain circuitry, which is altered in depression. However, such findings seem to vary not only by genotype but also by age, sex, and severity of symptoms, and are also reliant on good quality measures of adversity and depression $[18,20]$.

Two interrelated neural circuits and associated modulatory systems have been closely linked to risk for depression. One circuit connects the amygdala to the hippocampus and ventral expanses of the prefrontal cortex (PFC) and is linked to hypothalamic-pituitaryadrenal (HPA) axis activity. Disruption of this circuit links depression to stress-related enhancements in HPA- 
stress systems, such as higher than expected cortisol concentrations, and activity in the serotonergic system. Psychosocial stress, sex hormones and development have also been linked to changing activity in this circuit, with evidence that this circuit matures after adolescence. High concentrations of sex steroid receptors have been identified within this circuit and might provide a biological mechanism for why girls have higher risk of depression than boys. The other key circuit implicated in depression encompasses the striatum and its connection to both the PFC and ventral dopamine-based systems. Like the first circuit, this one also continues to mature through adolescence. Sex differences emerge in both circuits. Research into this reward circuit implies that reduced activity is linked with expression of and risk for depression. Reduced striatal and PFC activity during tasks involving rewards has been recorded both in individuals with major depression and in those with depressed parents. Both inherited factors and stress-related perturbations seem to contribute to these changes [18, 21].

Temperament and character traits are also important factors in the pathogenesis of depression in adolescence. According to Cloninger, temperament is responsible for automatic and emotional responses to environmental stimuli and encompasses four dimensions: novelty seeking, exploratory activity, harm avoidance, reward dependence and persistence [22]. In contrast, character develops across the lifespan and is influenced by social and cultural experiences. Three dimensions are distinguished: self-directedness, cooperativeness and selftranscendence [23]. Studies showed that depressed patients present higher novelty seeking, harm avoidance and lower reward dependence, persistence, selfdirectedness and cooperativeness compared to healthy individuals $[23,24]$.

\section{Diagnosis}

Primary care providers are frequently the first contact during times of distress and can be crucial to identify mental health issues allowing for an earlier depression diagnosis, treatment and referral [2].

The symptoms can differ from the adult population. In comparison to it, adolescents tend to have more frequently somatic symptoms, anxiety, disruptive behaviour and personality disorders [25].

The fact that these symptoms are common in other disorders such as hypothyroidism, anaemia, sleep apnoea or other chronic diseases makes the diagnosis more challenging to establish in these subjects [26].

\section{Screening tools}

The screening of adolescents for depression is an essential tool for early detection of this disorder. USPSTF and
AAP recommend the screening of adolescents in primary care settings [2-4, 25-27].

The Beck Depression Inventory (BDI) and Patient Health Questionnaire for Adolescents (PHQ-A) are the most commonly used, outperforming other screening tools in the identification of major depressive disorder among adolescents [2, 28].

Originally developed as a depression symptom rating scale for the adult population, BDI is widely used among adults and adolescents and mainly in research. It is a 21item self-report measure of depressive symptoms, scored from "0" to "3". Participants are asked to respond to each item based on their experiences within the past 2 weeks. The total score can range from 0 to 63 , with higher scores meaning higher levels of depressive symptoms [29]. In primary care settings, an adapted version (BDI-PC) is often used, which consists of a 7-item selfreport instrument, with a cut-off of 4 points for major depression [30]. Good performance has also been shown using BDI, with sensitivity ranging from 84 to $90 \%$ and specificity ranging from 81 to $86 \%$ [3].

The PHQ-A is the depression module of a 67 -item questionnaire that can be used to screen for depression among adolescent primary care patients. Composed of 9 questions, it can be entirely self-administered by the patient and evaluates symptoms experienced in the 2 weeks prior. It measures functional impairment and inquiries about suicidal ideation and suicide attempts [31]. The PHQ-A study had the highest positive predictive value, as well as a sensitivity and specificity of $73 \%$ and $94 \%$, respectively [3].

\section{Diagnostic tools}

Diagnosis of depression in adolescents is established through the criteria described in the Diagnostic and Statistical Manual of Mental Disorders, Fifth Edition (DSM-5) [32]. The evaluation of patients should be made through interviews, alone and with the patient's family and/or caregivers and should include an assessment of functional impairment in different domains and other existing psychiatric conditions [4].

DSM-5 establishes the diagnosis of major depressive disorder as a period of at least 2 weeks during which there is a depressed mood or the loss of interest or pleasure in nearly all activities, and, additionally, at least four additional symptoms from a list that includes changes in weight, sleep disturbances, changes in psychomotor activity, fatigue, feelings of worthlessness or guilt, impaired concentration or ability to make decisions, or suicidal ideation. Additionally, it states that, in adolescents, depressed mood can be replaced by irritability or crankiness, a sign that can be neglected during assessment or by caregivers. This presentation should be differentiated from a pattern of irritability when 
frustrated [33]. Children diagnosed with disruptive mood dysregulation disorder, a new diagnosis referring persistent irritability and frequent episodes of extreme behaviour, typically develop unipolar depressive or anxiety disorders as they mature into adolescence [32]. Clinical presentation differs between genders, with female adolescents reporting feelings of sadness, loneliness, irritability, pessimism, self-hatred and eating disorders, while males present with somatic complaints, reduced ability to think or concentrate, lacking decision making skills, restlessness and anhedonia [34, 35].

The severity of depressive disorders can be based on symptom count or intensity, and/or level of impairment. Mild depression can be defined as 5 to 6 symptoms that are mild in severity, with mild impairment in functioning. Severe depression exists when a patient experiences all depressive symptoms listed in the DSM-5 or severe impairment in functioning and, also, with at least 5 criteria and a specific suicide plan, clear intent or recent suicide attempt, psychotic symptoms or family history of first-degree relatives with bipolar disorder. Moderate depression falls between these two categories [4].

\section{Differential diagnosis}

Despite its well-defined diagnostic criteria, depression during adolescence can often be misdiagnosed, with the main differential diagnoses being adjustment disorder, dysthymic disorder, bipolar disorder and schizophrenia. However, it is crucial to establish the correct diagnosis as different psychiatric disorders involve distinct treatment and prognosis.

Adjustment disorder is classified as depressed mood in response to an identifiable psychosocial stressor. It arises within 3 months of the onset of a stressor and persists up to 6 months after stressor resolution. It is characterized by low mood, tearfulness, or hopelessness associated with a significant distress that exceeds what would be expected given the nature of the stressor, or impaired social or occupational functioning. On the other hand, dysthymic disorder is a pattern of chronic symptoms of depression that are present for most of the time on most days with a minimum duration of 1 year for children and adolescents [32].

Bipolar disorder and schizophrenia are much less common in adolescents compared to depression disorder. However, they have different prognosis and require different treatments. Consequently, when establishing the diagnosis of depressive disorder in adolescence, it is important to bear in mind that the first symptomatic episode may also represent the beginning of a bipolar disorder [36, 37].

\section{Management and treatment}

The treatment of depression in adolescence can include psychotherapy, pharmacotherapy or both [38]. Treatment should be selected based on the severity of the condition, the preference of the patient/family, associated risk factors, family support and the availability of each therapy $[39,40]$. On first approach, it is essential to comprehensively explain the therapeutic strategy and involve both patients and family members to assure close follow-up of progress, treatment adjustment according to symptoms and prevention of relapse [41]. Adolescents with moderate to severe depression, substance abuse, psychiatric disorders, suicidal ideation or resistance to treatment should be referred for specialized evaluation [42].

Treatment may be divided into three phases: acute (obtain response and remission), continuation (consolidate the response) and maintenance (avoid recurrences) [39]. Each of them must include psychoeducation, supportive approach and family involvement $[39,40]$.

In mild depression, psychotherapy may be the first option, complemented with pharmacotherapy if there is no response [42, 43]. The AAP recommends starting with active support, symptom monitoring and close follow-up for $6-8$ weeks [44]. These measures are also useful when patients refuse more interventional treatments. The $\mathrm{Na}$ tional Institute for Health and Care Excellence (NICE) has a slightly stricter approach, in which it recommends psychotherapy after absence of improvement after 2 weeks of watchful waiting [45]. In adolescents with moderate to severe depression, treatment is based on combined psychotherapy and pharmacotherapy [42, 43]. NICE recommends psychotherapy for the minimum of 3 months, followed by fluoxetine if necessary. AAP has a similar approach $[44,45]$. Other strategies such as physical exercise, sleep hygiene and adequate nutrition have been referred as treatment adjuvants [44, 46, 47].

Both NICE and AAP recommend treatment for at least 6 months after remission of symptoms to consolidate the response and prevent relapse (continuation phase). In addition, both organizations also recommend maintaining follow-up during 1 year or, in cases of recurrent depression, 2 years [44, 45].

\section{Psychotherapy}

In this area, Cognitive Behavioural Therapy (CBT) and Interpersonal Therapy (IPT) have shown effectiveness $[40,48]$.

CBT is a brief psychotherapy, carried out individually or in groups, based on the relationship between thoughts, feelings and behaviours [40]. CBT focuses on cognitive distortions associated with depressive mood and the development of behavioural activation techniques, coping strategies and problem solving [42]. When used in acute depression, it has been shown to have a moderate effect [40]. CBT seems to be useful in preventing relapses and suicidal ideation, in the 
treatment of resistant depression and in adolescents with long-term physical conditions [49-51]. Moreover, the combination of psychotherapy and pharmacotherapy, in particular fluoxetine, has shown promising results [52]. Within the different psychotherapy approaches, behavioural activation, challenging thoughts and involvement of caregivers have a higher success rate [53].

IPT assumes depression association with disruptive relationships, based on the negative impact of symptoms on interpersonal relationships and vice-versa [40]. This approach may be useful especially when there is a wellestablished relational factor as the cause of the depressive condition [54]. Most studies have compared only IPT with placebo groups or with other psychotherapy, showing favourable results for IPT $[48,55]$.

Psychotherapy should be considered first line of treatment in adolescents afraid of or with contraindications for medication, with identified stress factors or those with poor response to other approaches [56]. There are no contraindications to psychotherapy, though it has a limited effect in cases of cognitive delay [40].

\section{Pharmacotherapy}

Even though psychotherapy is an important component, pharmacotherapy can be used as an addition. When psychotherapy is not available or cannot be applied, pharmacotherapy can be an alternative [39, 41].

Fluoxetine is widely regarded as the first-line drug for this age group given its efficacy [2, 38, 57-59]. Besides fluoxetine, escitalopram has also shown to be particularly effective, especially for ages between 12 and 17 years $[38,60-62]$. The main side effects of selective serotonin receptor inhibitors (SSRIs) include abdominal pain, agitation, jitteriness, restlessness, diarrhoea, headache, nausea and changes in sleep patterns. However, these effects are dose dependent and tend to decrease over time [39].

Given the efficacy of fluoxetine and escitalopram, many studies have focused on other SSRIs, such as sertraline, citalopram, paroxetine and fluvoxamine. Citalopram must be carefully evaluated as side effects include prolongation of the QT interval, which can lead to arrhythmia [63, 64]. Paroxetine and fluvoxamine are not commonly used due to a lack of efficacy in this age group $[65,66]$. Regarding serotonin noradrenaline

Table 1 Drugs typically used in the treatment of depression in adolescence

\begin{tabular}{lll}
\hline Drug name & Starting dose $(\mathrm{mg})$ & Therapeutic dose range $(\mathrm{mg})$ \\
\hline Fluoxetine & 10 & $10-40$ \\
Escitalopram & 10 & 10 \\
Sertraline & 25 & $25-200$ \\
Citalopram & 10 & $10-40$ \\
\hline
\end{tabular}

receptor inhibitors (SNRIs), venlafaxine appears to have a similar efficacy to SSRIs in resistant depression and no significant differences in adverse effects [49]. However, because hypertension is a possible side effect, this parameter must be periodically evaluated [41, 64]. In Table 1 , the main drugs used in the treatment of depression in adolescents are displayed.

Bupropion and duloxetine have also been studied as alternatives but the evidence of its use in adolescents is limited. Bupropion can be useful in the treatment of overweight patients or those who intend to quit smoking. The main side effects are insomnia, agitation and seizures [41]. Bupropion is contraindicated in patients suffering from eating disorders. Duloxetine can be used for comorbid depression and pain in adolescents [67].

Tricyclic antidepressants do not have any demonstrated benefit in the treatment of depression in adolescents [42, 68,69]. This drug class has significant side effects such as dry mouth, orthostatic hypotension, tremors and vertigo and can increase PR interval and QRS duration. Moreover, it is highly lethal in overdose [69].

At the time of writing, only fluoxetine (ages 8 years and older) and escitalopram (ages 12 years and older) are approved by the Food and Drug Administration for the treatment of depression in children and adolescents $[70,71]$.

Several studies suggest an association between antidepressants and increased suicidal risk [18, 58]. However, the risks and benefits of this strategy should be evaluated. Adolescents should be closely monitored, and, if suicidal thoughts arise during treatment, parents should seek care as soon as possible, to adjust dosage, change antidepressant or discontinue it [42].

Finally, the treatment strategies proposed in this age group are illustrated in Fig. 1.

\section{Prevention}

Prevention is crucial to depression management, consequence of the impact on the population and inequal quality health care access [72]. In addition, it prevents the onset of other possible comorbidities, as well as reduces the impact on the patient and their families [7375].

It is important to understand which different risk factors and protective factors intervene in the development of the disease. The risk factors can be divided into specific and non-specific for depression. Regarding the specific ones, parent depression history increases the risk between 2 and 4 times [76]. Among the non-specific, poverty, domestic violence and child abuse also increase the risk. On the other hand, protective factors are good family support, emotional skills or coping ability [77]. 


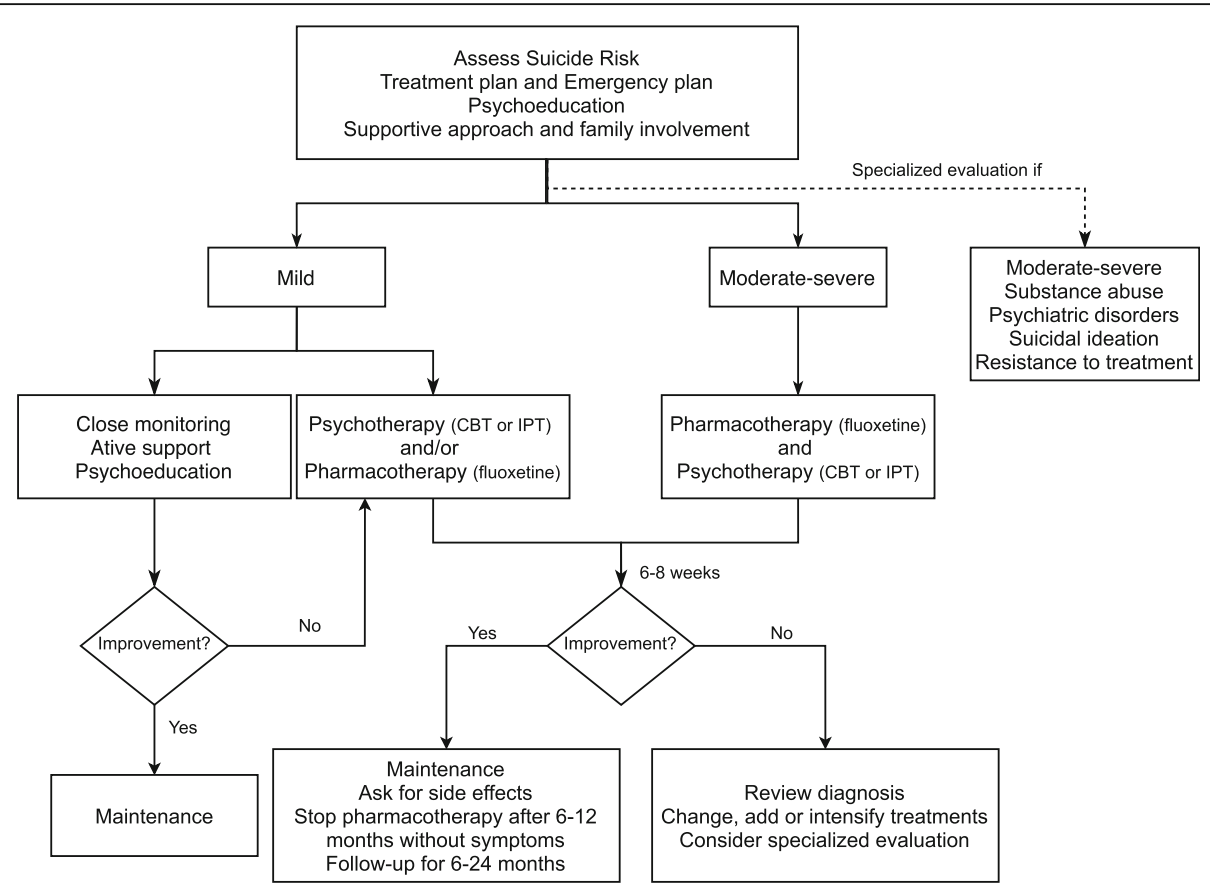

Fig. 1 Algorithm for the management and treatment of depression in adolescents

Depression prevention can be divided into 3 types: universal, selective and indicated. Universal interventions target the adolescent population group in general. Selective interventions target adolescents who are at risk for developing depression. Finally, indicated interventions target adolescents with subclinical symptoms of depression [78].

With regard to universal interventions, the efficacy of prevention programs through therapy for problem solving and overcoming traumatic situations has been demonstrated in multiple studies [79, 80]. Although it has been shown that adolescents under these programs experience decreased depressive symptoms, the long-term usefulness of these programs was not unanimous. The inclusion of parents to these programs provided no additional advantage [81]. Furthermore, no significant difference between adolescents who received an intervention program and those who did not was found, although improvements in school environment were reported [82].

Concerning selective interventions, interpersonal communication skills and optimistic thinking programs have shown to be effective in decreasing anxiety and depression [83]. Contrary to universal interventions, the inclusion of parents in programs was demonstrated as beneficial [83-85]. However, it had no benefit to adolescents, but improved the parents' perception of children's behaviour [86].

Finally, in indicated interventions, psychoeducation and skill development programs to overcome interpersonal issues and role disputes among adolescents have been carried out $[87,88]$. It was shown that symptoms improved significantly compared at the end of the program [87]. Additionally, the number of adolescents with suicidal ideations decreased.

Comparing different groups of programs, various meta-analyses have found that selective and indicated programs are more effective than universal ones $[89,90]$. These prevention programs are more effective when started between the ages of 11 and 15 [78]. However, their superiority is not unanimous [91].

\section{Conclusion}

Depression in adolescence can be a complex diagnosis and requires individual and oriented treatment. For this reason, early identification, treatment initiation and prompt referral to mental health specialists is crucial for the prognosis of these patients.

Due to the variety of its main clinical manifestations and the lack of diagnostic tests that fully and accurately establish the definite diagnosis, this process can be particularly challenging. Additionally, several differential diagnoses must be made to provide an accurate course of treatment.

Treatment options can include both psychotherapy (CBT or IPT) and pharmacotherapy. The most promising results are observed with the combination of psychotherapy and pharmacotherapy, mainly fluoxetine.

Nevertheless, the authors would like to highlight certain aspects that require improvement and implementation in daily practice in comparison with the presented 
recommendations in this publication. First, although Cognitive Behavioral Therapy is one of the most studied therapeutic orientations, the reproducibility of performance among professionals is limited and relies on the relationship established between the mental health professional and the patient, in a deeper way compared to pharmacotherapy. The scarce number of professionals and the absence of choice by the user may not allow the development of this interpersonal bond. This limitation is particularly important in the case of children and adolescents, who are in a period of transition in their physical and mental development, and whose psychological intervention can have a significant positive or negative impact with potential future repercussions. Second, most of the prevention programs described in the literature are not currently implemented. Finally, approaching the family environment is essential in the implementation of effective long-term therapeutic interventions, especially in the presence of a dysfunctional structure. Although recommended, its practical application is often difficult due to the need of active participation of family members, inside and outside the clinical office. Prevention, early diagnosis and treatment of depression in adolescence should be considered worldwide objectives, and the implementation of straightforward, effective and cost-conscious strategies for achieving such purposes is essential. Amongst these objectives, prevention is of utter importance and must be a priority when defining political strategies and governmental programs related to mental health.

\section{Abbreviations}

USPSTF: US Preventive Services Task Force; AAP: American Academy of Pediatrics; PFC: Prefrontal cortex; HPA: Hypothalamic-pituitary-adrenal; BDI: Beck Depression Inventory; PHQ-A: Patient Health Questionnaire fo Adolescents; BDI-PC: Beck Depression Inventory for Primary Care; DSM5: Diagnostic and Statistical Manual of Mental Disorders, Fifth Edition; CBT: Cognitive Behavioral Therapy; IPT: Interpersonal Therapy; SSRIs: Selective Serotonin Reuptake Inhibitors

\section{Acknowledgments}

The authors would like to thank Dilermando Sobral, MD, Sónia Almeida, MD and Paula Assunção, MD for their guidance.

\section{Authors' contributions}

DB conceived the original idea of this work and took the lead in writing the manuscript. All authors contributed equally in the literature review and writing of the manuscript. DB was responsible for the section on epidemiology and comorbidities. HM was responsible for the sections on the background and pharmacological treatment. MA was responsible for the abstract, non-pharmacological treatment and the conclusion. AL was responsible for the sections on methods and pathogenesis. CM was responsible for the sections on diagnosis and background, and FVB for the section on prevention. DB and HM were responsible for the construction of the final version of the manuscript which was reviewed and approved by all co-authors.

\section{Funding}

No sources of funding were required.

Availability of data and materials

Not applicable.
Ethics approval and consent to participate

Not applicable.

Consent for publication

Not applicable.

\section{Competing interests}

The authors declare that they have no competing interests

\section{Author details}

${ }^{1}$ Family Health Unit of Ramalde, Health Centres Grouping of Porto Ocidental, Porto, Portugal. ' FP-ENAS-Energy, Environment and Health Research Unit/ CEBIMED- Centro de Estudos em Biomedicina, Fernando Pessoa University, Porto, Portugal.

Received: 12 June 2020 Accepted: 21 August 2020

Published online: 02 October 2020

References

1. Costello EJ, Egger H, Angold A (2005) 10-year research update review: the epidemiology of child and adolescent psychiatric disorders: I. Methods and public health burden. J Am Acad Child Adolesc Psychiatry 44(10):972-986. https://doi.org/10.1097/01.chi.0000172552.41596.6f

2. Forman-Hoffman V, McClure E, McKeeman J, Wood CT, Middleton JC, Skinner AC, Perrin EM, Viswanathan M (2016) Screening for major depressive disorder in children and adolescents: a systematic review for the US preventive services task force. Ann Intern Med 164(5):342. https://doi.org/10. $7326 / \mathrm{m} 15-2259$

3. Siu AL, USPSTF (2016) Screening for depression in children and adolescents: US preventive services task force recommendation statement. Pediatrics 137(3). https://doi.org/10.1542/peds.2015-4467

4. Zuckerbrot RA, Cheung A, Jensen PS, Stein REK, Laraque D (2018) Guidelines for adolescent depression in primary care (GLAD-PC): part I - practice preparation, identification, assessment, and initial management. Pediatrics 141 (3):pii:e20174081. https://doi.org/10.1542/peds.2017-4081

5. Costello EJ, Foley DL, Angold A (2006) 10-year research update review: the epidemiology of child and adolescent psychiatric disorders: II. Developmental epidemiology. J Am Acad Child Adolesc Psychiatry 45(1):825. https://doi.org/10.1097/01.chi.0000184929.41423.c0

6. Green H, McGinnity A, Meltzer H, Ford T, Goodman R (2005) Mental health of children and young people in Great Britain, 2004. Palgrave Macmillan, Hampshire

7. Perou R, Bitsko RH, Blumberg SJ, Pastor P, Ghandour RM, Gfroerer JC, Hedden SL, Crosby AE, Visser SN, Schieve LA, Parks SE, Hall JE, Brody D, Simile CM, Thompson WW, Baio J, Avenevoli S, Kogan MD, Huang LN (2013) Mental health surveillance among children - United States, 2005-2011. MMWR Suppl 62(2):1-35

8. Wesselhoeft R, Sorensen MJ, Heiervang ER, Bilenberg N (2013) Subthreshold depression in children and adolescents - a systematic review. J Affect Disord 151(1):7-22. https://doi.org/10.1016/j.jad.2013.06.010

9. Blakemore SJ (2008) The social brain in adolescence. Nat Rev Neurosci 9(4): 267-277. https://doi.org/10.1038/nrn2353

10. Nelson EE, Leibenluft E, McClure EB, Pine DS (2005) The social re-orientation of adolescence: a neuroscience perspective on the process and its relation to psychopathology. Psychol Med 35(2):163-174. https://doi.org/10.1017/ s0033291704003915

11. Patton GC, Viner R (2007) Pubertal transitions in health. Lancet 369(9567): 1130-1139. https://doi.org/10.1016/s0140-6736(07)60366-3

12. Avenevoli S, Swendsen J, He JP, Burstein M, Merikangas KR (2015) Major depression in the national comorbidity survey-adolescent supplement: prevalence, correlates, and treatment. J Am Acad Child Adolesc Psychiatry 54 (1):37-44.e32. https://doi.org/10.1016/j.jaac.2014.10.010

13. Hyde JS, Mezulis AH, Abramson LY (2008) The ABCs of depression: integrating affective, biological, and cognitive models to explain the emergence of the gender difference in depression. Psychol Rev 115(2):291313. https://doi.org/10.1037/0033-295x.115.2.291

14. Seedat S, Scott KM, Angermeyer MC, Berglund P, Bromet EJ, Brugha TS, Demyttenaere K, de Girolamo G, Haro JM, Jin R, Karam EG, Kovess-Masfety V, Levinson D, Medina Mora ME, Ono Y, Ormel J, Pennell BE, Posada-Villa J, Sampson NA, Williams D, Kessler RC (2009) Cross-national associations between gender and mental disorders in the world health organization 
world mental health surveys. Arch Gen Psychiatry 66(7):785-795. https://doi. org/10.1001/archgenpsychiatry.2009.36

15. Angold A, Costello EJ, Erkanli A, Worthman CM (1999) Pubertal changes in hormone levels and depression in girls. Psychol Med 29(5):1043-1053. https://doi.org/10.1017/s0033291799008946

16. Cairns KE, Yap MB, Pilkington PD, Jorm AF (2014) Risk and protective factors for depression that adolescents can modify: a systematic review and metaanalysis of longitudinal studies. J Affect Disord 169:61-75. https://doi.org/10. 1016/j.jad.2014.08.006

17. Boden JM, Fergusson DM, Horwood LJ (2010) Cigarette smoking and depression: tests of causal linkages using a longitudinal birth cohort. $\mathrm{Br} \mathrm{J}$ Psychiatry 196(6):440-446. https://doi.org/10.1192/bjp.bp.109.065912

18. Thapar A, Collishaw S, Pine DS, Thapar AK (2012) Depression in adolescence. Lancet 379(9820):1056-1067. https://doi.org/10.1016/S0140-6736(11)60871-4

19. Trent ES, Viana AG, Raines EM, Woodward EC, Storch EA, Zvolensky MJ (2019) Parental threats and adolescent depression: the role of emotion dysregulation. Psychiatry Res 276:18-24. https://doi.org/10.1016/j.psychres.2019.04.009

20. Risch N, Herrell R, Lehner T, Liang KY, Eaves L, Hoh J, Griem A, Kovacs M, Ott J, Merikangas KR (2009) Interaction between the serotonin transporter gene (5-HTTLPR), stressful life events, and risk of depression: a meta-analysis. JAMA 301(23):2462-2471. https://doi.org/10.1001/jama.2009.878

21. Forbes EE, Dahl RE (2005) Neural systems of positive affect: relevance to understanding child and adolescent depression? Dev Psychopathol 17(3): 827-850. https://doi.org/10.1017/s095457940505039x

22. Cloninger CR, Svrakic DM, Przybeck TR (1993) A psychobiological model of temperament and character. Arch Gen Psychiatry 50(12):975-990. https:// doi.org/10.1001/archpsyc.1993.01820240059008

23. Nogueira BS, Fraguas R Júnior, Benseñor IM, Lotufo PA, Brunoni AR (2017) Temperament and character traits in major depressive disorder: a case control study. Sao Paulo Med J 135 (5)469-74. https://doi.org/10.1590/15163180.2017.0063250517

24. Zappitelli MC, Bordin IA, Hatch JP, Caetano SC, Zunta-Soares G, Olvera RL, Soares JC (2013) Temperament and character traits in children and adolescents with major depressive disorder: a case-control study. Compr Psychiatry 54(4):346-353. https://doi.org/10.1016/j.comppsych.2012.10.009

25. Nardi B, Francesconi G, Catena-Dell'Osso M, Bellantuono C (2013) Adolescent depression: clinical features and therapeutic strategies. Eur Rev Med Pharmacol Sci 17(11):1546-1551

26. Bilello JA (2016) Seeking an objective diagnosis of depression. Biomark Med 10(8):861-875. https://doi.org/10.2217/bmm-2016-0076

27. Mäki M, Mustalahti K, Kokkonen J, Kulmala P, Haapalahti M, Karttunen T, Ilonen J, Laurila K, Dahlbom I, Hansson T, Höpfl P, Knip M (2003) Prevalence of Celiac disease among children in Finland. N Engl J Med 348(25):25172524. https://doi.org/10.1056/NEJMoa021687

28. Maurer DM, Raymond TJ, Davis BN (2018) Depression: screening and diagnosis. Am Fam Physician 98(8):508-515

29. Stockings E, Degenhardt L, Lee YY, Mihalopoulos C, Liu A, Hobbs M, Patton $G$ (2015) Symptom screening scales for detecting major depressive disorder in children and adolescents: a systematic review and meta-analysis of reliability, validity and diagnostic utility. J Affect Disord 174:447-463. https:// doi.org/10.1016/j.jad.2014.11.061

30. Beck AT, Guth D, Steer RA, Ball R (1997) Screening for major depression disorders in medical inpatients with the beck depression inventory for primary care. Behav Res Ther 35(8):785-791. https://doi.org/10.1016/s0005-7967(97)00025-9

31. Johnson JG, Harris ES, Spitzer RL, Williams JBW (2002) The patient health questionnaire for adolescents: validation of an instrument for the assessment of mental disorders among adolescent primary care patients. J Adolesc Health 30(3):196-204. https://doi.org/10.1016/s1054-139x(01)00333-0

32. American Psychiatric Association. Diagnostic and statistical manual of mental disorders, 5th edition: DSM-5 (2013). 5th edn. American Psychiatric Publishing, Arlington.

33. Orchard F, Pass L, Marshall T, Reynolds S (2017) Clinical characteristics of adolescents referred for treatment of depressive disorders. Child Adolesc Ment Health 22(2):61-68. https://doi.org/10.1111/camh.12178

34. Kovacs M, Obrosky DS, Sherrill J (2003) Developmental changes in the phenomenology of depression in girls compared to boys from childhood onward. J Affect Disord 74(1):33-48. https://doi.org/10.1016/50165-0327(02)00429-9

35. Price RB, Rosen D, Siegle GJ, Ladouceur CD, Tang K, Allen KB, Ryan ND, Dahl RE, Forbes EE, Silk JS (2016) From anxious youth to depressed adolescents: prospective prediction of 2-year depression symptoms via attentional bias measures. J Abnorm Psychol 125(2):267-278. https://doi.org/10.1037/abn0000127
36. Lewinsohn PM, Klein DN, Seeley JR (1995) Bipolar disorders in a community sample of older adolescents: prevalence, phenomenology, comorbidity, and course. J Am Acad Child Adolesc Psychiatry 34(4):454-463

37. Thapar A, Pine D, Leckman JF, Scott S, Snowling MJ, Taylor EA (2017) Rutter's child and adolescent psychiatry, 6th edn. Wiley-Blackwell, Oxford, UK

38. Selph SS, McDonagh MS (2019) Depression in children and adolescents: evaluation and treatment. Am Fam Physician 100(10):609-617

39. Birmaher B, Brent D (2007) Practice parameter for the assessment and treatment of children and adolescents with depressive disorders. J Am Acad Child Adolesc Psychiatry 46(11):1503-1526. https://doi.org/10.1097/chi. Ob013e318145ae1c

40. Cheung AH, Kozloff N, Sacks D (2013) Pediatric depression: an evidencebased update on treatment interventions. Curr Psychiatry Rep 15(8):381. https://doi.org/10.1007/s11920-013-0381-4

41. Richardson LP, Katzenellenbogen R (2005) Childhood and adolescent depression: the role of primary care providers in diagnosis and treatment. Curr Probl Pediatr Adolesc Health Care 35(1):6-24. https://doi.org/10.1016/j. cppeds.2004.09.001

42. Clark MS, Jansen KL, Cloy JA (2012) Treatment of childhood and adolescent depression. Am Fam Physician 86(5):442-448

43. Lewandowski RE, Acri MC, Hoagwood KE, Olfson M, Clarke G, Gardner W, Scholle SH, Byron S, Kelleher K, Pincus HA, Frank S, Horwitz SM (2013) Evidence for the management of adolescent depression. Pediatrics 132(4): e996-e1009. https://doi.org/10.1542/peds.2013-0600

44. Cheung AH, Zuckerbrot RA, Jensen PS, Laraque D, Stein REK (2018) Guidelines for adolescent depression in primary care (GLAD-PC): part II treatment and ongoing management. Pediatrics 141(3):e20174082. https:// doi.org/10.1542/peds.2017-4082

45. National Institute for Health and Care Excellence (2019) Depression in children and young people: identification and management (NICE Guideline 134). Available at: https://www.nice.org.uk/guidance/ng134 [.

46. Bailey AP, Hetrick SE, Rosenbaum S, Purcell R, Parker AG (2018) Treating depression with physical activity in adolescents and young adults: a systematic review and meta-analysis of randomised controlled trials. Psychol Med 48(7):1068-1083. https://doi.org/10.1017/s0033291717002653

47. Radovic S, Gordon MS, Melvin GA (2017) Should we recommend exercise to adolescents with depressive symptoms? A meta-analysis. J Paediatr Child Health 53(3):214-220. https://doi.org/10.1111/jpc.13426

48. Zhou X, Hetrick SE, Cuijpers P, Qin B, Barth J, Whittington CJ, Cohen D, Del Giovane C, Liu Y, Michael KD, Zhang Y, Weisz JR, Xie P (2015) Comparative efficacy and acceptability of psychotherapies for depression in children and adolescents: a systematic review and network meta-analysis. World Psychiatry 14(2):207-222. https://doi.org/10.1002/wps.20217

49. Brent D, Emslie G, Clarke G, Wagner KD, Asarnow JR, Keller M, Vitiello B, Ritz L, lyengar S, Abebe K, Birmaher B, Ryan N, Kennard B, Hughes C, DeBar L, McCracken J, Strober M, Suddath R, Spirito A, Leonard H, Melhem N, Porta G, Onorato M, Zelazny J (2008) Switching to another SSRI or to venlafaxine with or without cognitive behavioral therapy for adolescents with SSRIresistant depression: the TORDIA randomized controlled trial. JAMA 299(8): 901-913. https://doi.org/10.1001/jama.299.8.901

50. Thabrew H, Stasiak K, Hetrick SE, Donkin L, Huss JH, Highlander A, Wong S, Merry SN (2018) Psychological therapies for anxiety and depression in children and adolescents with long-term physical conditions. Cochrane Database Syst Rev 12:CD012488. https://doi.org/10.1002/14651858.CD012488.pub2

51. Vitiello B, Brent DA, Greenhill LL, Emslie G, Wells K, Walkup JT, Stanley B, Bukstein O, Kennard BD, Compton S, Coffey B, Cwik MF, Posner K, Wagner A, March JS, Riddle M, Goldstein T, Curry J, Capasso L, Mayes T, Shen S, Gugga SS, Turner JB, Barnett S, Zelazny J (2009) Depressive symptoms and clinical status during the treatment of adolescent suicide attempters (TASA) study. J Am Acad Child Adolesc Psychiatry 48(10):997-1004. https://doi.org/ 10.1097/CHI.0b013e3181b5db66

52. March J, Silva S, Petrycki S, Curry J, Wells K, Fairbank J, Burns B, Domino M, McNulty S, Vitiello B, Severe J (2004) Fluoxetine, cognitive-behavioral therapy, and their combination for adolescents with depression: Treatment for Adolescents With Depression Study (TADS) randomized controlled trial. JAMA 292(7):807-820. https://doi.org/10.1001/jama.292.7.807

53. Oud M, de Winter L, Vermeulen-Smit E, Bodden D, Nauta M, Stone L, van den Heuvel M, Taher RA, de Graaf I, Kendall T, Engels R, Stikkelbroek Y (2019) Effectiveness of CBT for children and adolescents with depression: a systematic review and meta-regression analysis. European psychiatry 57:3345. https://doi.org/10.1016/j.eurpsy.2018.12.008 
54. Brunstein-Klomek A, Zalsman G, Mufson L (2007) Interpersonal psychotherapy for depressed adolescents (IPT-A). Isr J Psychiatry Relat Sci 44(1):40-46

55. Mufson L, Dorta KP, Wickramaratne P, Nomura Y, Olfson M, Weissman MM (2004) A randomized effectiveness trial of interpersonal psychotherapy for depressed adolescents. Arch Gen Psychiatry 61(6):577-584. https://doi.org/ 10.1001/archpsyc.61.6.577

56. Tompson MC, McNeil FM, Rea MM, Asarnow JR (2000) Identifying and treating adolescent depression. West J Med 172(3):172-176. https://doi.org/ 10.1136/ewjm.172.3.172

57. Cipriani A, Zhou X, Del Giovane C, Hetrick SE, Qin B, Whittington C, Coghill D, Zhang Y, Hazell P, Leucht S, Cuijpers P, Pu J, Cohen D, Ravindran AV, Liu Y, Michael KD, Yang L, Liu L, Xie P (2016) Comparative efficacy and tolerability of antidepressants for major depressive disorder in children and adolescents: a network meta-analysis. Lancet 388(10047):881-890. https:// doi.org/10.1016/S0140-6736(16)30385-3

58. Hetrick SE, Merry SN, McKenzie J, Sindahl P, Proctor M (2007) Selective serotonin reuptake inhibitors (SSRIs) for depressive disorders in children and adolescents. Cochrane Database Syst Rev 3:CD004851. https://doi.org/10. 1002/14651858.CD004851.pub2

59. Ignaszewski MJ, Waslick B (2018) Update on randomized placebo-controlled trials in the past decade for treatment of major depressive disorder in child and adolescent patients: a systematic review. J Child Adolesc Psychopharmacol 28(10):668-675. https://doi.org/10.1089/cap.2017.0174

60. Bridge JA, lyengar S, Salary CB, Barbe RP, Birmaher B, Pincus HA, Ren L, Brent DA (2007) Clinical response and risk for reported suicidal ideation and suicide attempts in pediatric antidepressant treatment: a meta-analysis of randomized controlled trials. JAMA 297(15):1683-1696. https://doi.org/10. 1001/jama.297.15.1683

61. Findling RL, Robb A, Bose A (2013) Escitalopram in the treatment of adolescent depression: a randomized, double-blind, placebo-controlled extension trial. J Child Adolesc Psychopharmacol 23(7):468-480. https://doi. org/10.1089/cap.2012.0023

62. Mullen S (2018) Major depressive disorder in children and adolescents. Ment Health Clin 8(6):275-283. https://doi.org/10.9740/mhc.2018.11.275

63. Czaja AS, Valuck RJ, Anderson HD (2013) Comparative safety of selective serotonin reuptake inhibitors among pediatric users with respect to adverse cardiac events. Pharmacoepidemiol Drug Saf 22(6):607-614. https://doi.org/ 10.1002/pds.3420

64. DeFilippis M, Wagner KD (2014) Management of treatment-resistant depression in children and adolescents. Pediatric Drugs 16(5):353-361. https://doi.org/10.1007/s40272-014-0088-y

65. Hetrick SE, McKenzie JE, Cox GR, Simmons MB, Merry SN (2012) Newer generation antidepressants for depressive disorders in children and adolescents. Cochrane Database Syst Rev 11:CD004851. https://doi.org/10. 1002/14651858.CD004851.pub3

66. Walkup JT, Labellarte MJ, Riddle MA, Pine DS, Greenhill L, Klein R, Davies M, Sweeney M, Abikoff H, Hack S (2001) Fluvoxamine for the treatment of anxiety disorders in children and adolescents. N Engl J Med 344(17):12791285. https://doi.org/10.1056/NEJM200104263441703

67. Meighen KG (2007) Duloxetine treatment of pediatric chronic pain and comorbid major depressive disorder. J Child Adolesc Psychopharmacol 17(1): 121-127. https://doi.org/10.1089/cap.2006.0042

68. Hazell P, Connell D, Heathcote D, Robertson J, Henry D (1995) Efficacy of tricyclic drugs in treating child and adolescent depression: a meta-analysis. BMJ 310(6984):897. https://doi.org/10.1136/bmj.310.6984.897

69. Hazell P, Mirzaie M (2013) Tricyclic drugs for depression in children and adolescents. Cochrane Database Syst Rev 6:CD002317. https://doi.org/10. 1002/14651858.CD002317.pub2

70. Eli Lilly and Company. Prozac (Fluoxetina) [Capsules]. U.S. Food and Drug Administration website https://www.accessdata.fda.gov/drugsatfda_docs/ label/2017/018936s108lbl.pdf. Revised 2017. Accessed 20 July, 2020.

71. H. Lundbeck A/S. Lexapro (Escitalopram) [Tablets]. U.S. Food and Drug Adminstration website https://www.accessdata.fda.gov/drugsatfda_docs/ label/2017/021323s047lbl.pdf. Revised 2017. Accessed 20 July, 2020.

72. Kakuma R, Minas H, Van Ginneken N, Dal Poz MR, Desiraju K, Morris JE, Saxena S, Scheffler RM (2011) Human resources for mental health care: current situation and strategies for action. The Lancet 378(9803):1654-1663. https://doi.org/10.1016/S0140-6736(11)61093-3

73. Cuijpers P, van Straten A, Smit F, Mihalopoulos C, Beekman A (2008) Preventing the onset of depressive disorders: a meta-analytic review of psychological interventions. Am J Psychiatry 165(10):1272-1280. https://doi. org/10.1176/appi.ajp.2008.07091422

74. Judd LL (1997) The clinical course of unipolar major depressive disorders. Arch Gen Psychiatry 54(11):989-991. https://doi.org/10.1001/archpsyc.1997. 01830230015002

75. Panel DG (1994) Depression in primary care: detection, diagnosis, and treatment. J Am Assoc Nurse Pract 6(5):224-238. https://doi.org/10.1111/j. 1745-7599.1994.tb00946.x

76. Evans DL, Andrews LW (2005) Adolescent mental health initiative. In: If your adolescent has depression or bipolar disorder: an essential resource for parents. Press, Oxford University

77. England MJ, Sim $\sqcup$, Council NR (2009) The etiology of depression. In: Depression in parents, parenting, and children: opportunities to improve identification, treatment, and prevention. National Academies Press (US), pp 73-118

78. O'Connell ME, Boat T, Warner KE (2009) Preventing mental, emotional, and behavioral disorders among young people: progress and possibilities, vol 7. National Academies Press, Washington, DC

79. Spence SH, Sheffield JK, Donovan CL (2003) Preventing adolescent depression: an evaluation of the problem solving for life program. J Clin Child Psychol 71(1):3-13. https://doi.org/10.1037//0022-006x.71.1.3

80. Spence SH, Sheffield JK, Donovan CL (2005) Long-term outcome of a schoolbased, universal approach to prevention of depression in adolescents. J Consult Clin Psychol 73(1):160-167. https://doi.org/10.1037/0022-006X.73.1.160

81. Shochet IM, Dadds MR, Holland D, Whitefield K, Harnett PH, Osgarby SM (2001) The efficacy of a universal school-based program to prevent adolescent depression. J Clin Child Psychol 30(3):303-315. https://doi.org/10. 1207/S15374424JCCP3003_3

82. Sawyer MG, Pfeiffer S, Spence SH, Bond L, Graetz B, Kay D, Patton G, Sheffield J (2010) School-based prevention of depression: a randomised controlled study of the beyondblue schools research initiative. J Child Psychol Psychiatry 51(2): 199-209. https://doi.org/10.1111/j.1469-7610.2009.02136.x

83. Gillham JE, Reivich KJ, Freres DR, Lascher M, Litzinger S, Shatté A, Seligman ME (2006b) School-based prevention of depression and anxiety symptoms in early adolescence: a pilot of a parent intervention component. Sch Psychol Q 21(3):323-348. https://doi.org/10.1521/scpq.2006.21.3.323

84. Gillham JE, Brunwasser SM, Freres DR (2008) Preventing depression in early adolescence: the penn resiliency program. In: Handbook of depression in children and adolescents. The Guilford Press, New York, NY, US, pp 309-322

85. Gillham JE, Hamilton J, Freres DR, Patton K, Gallop R (2006a) Preventing depression among early adolescents in the primary care setting: a randomized controlled study of the Penn Resiliency Program. J Abnorm Child Psychol 34(2):203-219. https://doi.org/10.1007/s10802-005-9014-7

86. Roberts C, Ballantyne F, Van Der Klift P (2003) Aussie optimism. Curtin University of Technology, Perth, Australia, Social life skills. Teacher resource

87. Thompson EA, Eggert LL, Herting JR (2000) Mediating effects of an indicated prevention program for reducing youth depression and suicide risk behaviors. Suicide Life Threat Behav 30(3):252-271. https://doi.org/10. 1111/j.1943-278X.2000.tb00990.x

88. Young JF, Mufson L, Davies M (2006) Efficacy of interpersonal psychotherapy-adolescent skills training: an indicated preventive intervention for depression. J Child Psychol Psychiatry 47(12):1254-1262. https://doi.org/10.1111/j.1469-7610.2006.01667.x

89. Horowitz JL, Garber J (2006) The prevention of depressive symptoms in children and adolescents: a meta-analytic review. J Consult Clin Psychol 74(3):401-415. https://doi.org/10.1037/0022-006X.74.3.401

90. Stice E, Shaw H, Bohon C, Marti CN, Rohde P (2009) A meta-analytic review of depression prevention programs for children and adolescents: factors that predict magnitude of intervention effects. J Consult Clin Psychol 77(3): 486-503. https://doi.org/10.1037/a0015168

91. Merry SN, Hetrick SE, Cox GR, Brudevold-Iversen T, Bir JJ, McDowell H (2011) Psychological and educational interventions for preventing depression in children and adolescents. Cochrane Database Syst Rev 7(12):CD003380. https://doi.org/10.1002/14651858.CD003380.pub3

\section{Publisher's Note}

Springer Nature remains neutral with regard to jurisdictional claims in published maps and institutional affiliations. 